\title{
A generalizable monitoring model to implement policies to promote forest restoration - A case study in São Paulo - Brazil ${ }^{\text {is }}$
}

\author{
Silvana Ribeiro Nobre ${ }^{\mathrm{a}, *}$, José Guilherme Borges ${ }^{\mathrm{b}}$, Luis Diaz-Balteiro ${ }^{\mathrm{a}}$, \\ a UPM - Universidad Politécnica de Madrid, Departamento de Economía y Gestión Forestal, Spain \\ ${ }^{\mathrm{b}}$ UL - University of Lisbon, School of Agriculture, Forest Research Centre, Portugal \\ c USP - University of São Paulo, Department of Forest Science, Brazil \\ ${ }^{\mathrm{d}}$ Secretaria do Meio Ambiente de São Paulo, Brazil \\ e IPEF - Instituto de Pesquisas e Estudos Florestais, Piracicaba SP, Brazil
} Luiz Carlos Estraviz Rodriguez ${ }^{c}$, Helena Carrascosa von Glehn ${ }^{\mathrm{d}}$, Maria José Zakia ${ }^{\mathrm{e}}$

A R T I C L E I N F O

\section{Keywords:}

Adaptive management

Forest management decision support system

Forest restoration

Integrated forest planning

\begin{abstract}
A B S T R A C T
Examples of large-scale restoration programs to recover ecosystem services are now common in many countries, and governments are assuming ambitious forest restoration targets. Given the increasing investment of time, effort, and money in restoration, there is an urgent need to develop monitoring programs to assess restoration effectiveness. Some countries are already conducting monitoring programs, but the effectiveness of the restoration programs remains mostly unknown. Restoration evaluation often entails significant difficulties, such as the lack of harmonized monitoring data and imprecise information available about project goals and implementation. With the intent of contributing to the development of effective and accountable restoration projects, the objective of our work is to create a conceptual model that provides the building blocks of a planning and monitoring system to support forest restoration programs. The aim is to develop a conceptual model that represents forest restoration monitoring processes that effectively attain and measure the desirable outcomes. The São Paulo Forest Restoration Program is the case study that provides variables and processes to illustrate the development of the conceptual model. This paper presents the conceptual model, emphasizing generalizable principles that extend its applicability to similar monitoring programs. Based on action learning principles and recommendations from a comprehensive literature review, the resulting Forest Management Decisions Support System (FMDSS) embeds adaptive management strategies and the existence of an auto-updatable knowledge base. The result is a conceptual model that can be generalizable and applicable beyond the realms of the FMDSS. The restoration of degraded areas in a case with $>40,000$ rural properties serves as the case study. Although the planning and the monitoring of the restoration programs differ, the generalizable principles used to develop the conceptual model presented in this paper result in continuous intelligent monitoring processes that transform the systems so that they are adaptable to apparently different situations. Additionally, conceptual models that integrate adaptive planning and monitoring processes, supported by an auto-updatable knowledge base, mitigate the risk of failures, mainly when the comprehensive gathering of well-established references for the initial knowledge base has been conducted well at the outset.
\end{abstract}

\section{Introduction}

Examples of large-scale restoration programs to recover essential ecosystem services are now common in many countries. Governments are assuming ambitious targets outlined in regional and national forest restoration policies (e.g., Sao Paulo State Resolution SMA 32/2014, Brazil; Environmental Protection Law, China) as well as global commitments (Benini and de Adeodato, 2017; Ray et al., 2017; GaticaSaavedra et al., 2017). Additionally, an increasing interest in forest restoration can be seen in scientific literature in recent years (GaticaSaavedra et al., 2017).

Among other methods to reverse degradation and destruction, active forest restoration is increasingly being used. A great amount has been invested throughout the world on landscape restoration programs,

\footnotetext{
This article is part of a special issue entitled. "Models and tools for integrated forest management and forest policy analysis" published at the journal Forest Policy and Economics 103C, 2019.

* Corresponding author at: Calle de Robledillo, 10, Piso 1-7, 28003 Madrid, Spain.

E-mail address: silvana.rnobre@alumnos.upm.es (S.R. Nobre).
} 
and the New Climate Economy Report ${ }^{1}$ estimates that the total expenditure on these activities amounts to $\$ 50$ billion USD per year, half of this coming from developing countries (Benini and de Adeodato, 2017).

Demand for restoration in Brazil is increasing strongly (Benini and de Adeodato, 2017). Federal and State governments, NGOs, and the private sector have organized themselves in different types of coalitions after realizing the urgent need for the restoration of ecosystem services such water supply, soil, and biodiversity conservation (Viani et al., 2017). Among other initiatives, a national multi-stakeholder coalition (the Atlantic Forest Pact) was created with the goal of promoting the restoration of 15 million hectare in the Atlantic Forest biome by 2050 (Viani et al., 2017).

Given the increasing investment of time, effort, and money in restoration, there is an urgent need to develop monitoring programs to assess restoration effectiveness (Durigan et al., 2016; Gatica-Saavedra et al., 2017; Watson et al., 2017). Long-term monitoring programs at larger spatial scales are especially growing in importance and have specific challenges to overcome such as consistency, standardization, repeatability, affordability, and continuity (White et al., 2017; Reynolds et al., 2016; Gatica-Saavedra et al., 2017).

Gatica-Saavedra et al. (2017) conducted a literature review covering a total of 94 publications, between 1990 and 2015 that were filtered in their analysis. They found forest restoration assessments in 25 different countries and concluded that the effectiveness of most restoration programs remains mostly unknown, limiting the ability to determine the overall impact of current investments in restoration.

The most considerable number of assessments, according to GaticaSaavedra et al. (2017), was conducted in tropical forests. Published assessments increased considerably between 2010 and 2015 in all regions of the world. Forest composition and ecosystem functions were the most frequently cited attributes, found in $79 \%$ and $68 \%$ of the publications.

Although the number of assessments has increased over time in all regions, South America was the region with the most evident increase. The number of assessments was particularly high in Brazil, which leads South America in public policies and legislation aimed at increasing the effectiveness of forest restoration. Moreover, according to Durigan et al. (2016), forest restoration projects have grown not only in number but also in extension in Brazil over the recent years.

One of the most significant findings of the literature review conduct by Gatica-Saavedra et al. (2017) was the need for the use of a greater number of indicators of the effects of forest restoration. Unless a greater number is used, investigators might not be able to understand the extent to which management activities are contributing to restoring ecological complexity and integrity in forest ecosystems and contributing to achieving global conservation goals.

Restoration evaluation often entails significant difficulties such as the lack of harmonized monitoring data, lack of reference sites, and vague and imprecise information available about project goals and implementation (Ocampo-Melgar et al., 2016).

Therefore, despite the growing demand for data collected consistently across space and time, monitoring efforts fail frequently (Reynolds et al., 2016). Interestingly, one of the main failures simultaneously pointed at by Albert et al. (2015) and Reynolds et al. (2016) is that effective monitoring requires a remarkable plan phase and designed model to guarantee the link between the outcomes of the initiatives with the restoration policy program objectives. The key benefits of following a planning framework lie in providing a better basis for accounting and subsequent decision-making (Albert et al., 2015).

\footnotetext{
${ }^{1}$ The New Climate Economy was commissioned in 2013 by the governments of seven countries: Colombia, Ethiopia, Indonesia, Norway, South Korea, Sweden and the United Kingdom. The Commission has operated as an independent body and has been given full freedom to reach its own conclusions.
}

As a method for planning assessment programs, Reynolds et al. (2016) proposed a roadmap for designing and implementing successful biological monitoring programs. Their intended to address any monitoring program that aims to better natural resources management. The roadmap emphasizes linkages among core decisions to ensure alignment of all components, from problem framing through technical details of data collection and analysis (Reynolds et al., 2016).

The first phase of the roadmap is dedicated to clarifying the objectives and developing a conceptual model of the system. More specifically, the first phase comprises four steps (define the problem; state the objectives; design a conceptual model, and specify management actions); the second; and the third one describes how a conceptual model should be designed. Reynolds et al. (2016) also define a conceptual model as the intellectual foundation upon which a monitoring program rests.

Watson et al. (2017) developed a conceptual model that represents the many hypothesized links from two groups of facts: (1) on-ground connectivity management to organismal movement and (2) the demographic parameters that define population processes and conservation outcomes intended. Then they embedded this model within an adaptive management framework to provide a decision-support tool that linked policy program objectives to achievable monitoring goals, advising on the most appropriate methods to use for understanding, managing and reporting effects of connectivity restoration.

With the intent of contributing to the development of effective and accountable restoration projects, the objective of our work is to create a conceptual monitoring model that can be applied to the monitoring restoration program and can be embedded in the planning tool developed to support the forest restoration program of the state of São Paulo in Brazil. The primary objective of this paper is to present a monitoring model that can be generalized to address similar monitoring programs.

More precisely, the proposal follows the first phase of Reynolds et al. (2016), generating sufficient information to design the monitoring process model in the context of the São Paulo forest restoration program. Subsequently, the applicability of the model to more general cases is explained through references to other authors' experiences.

As in Watson et al. (2017), the proposed conceptual model is embeddable as an adaptive management framework into Forest Management Decision Support Systems (FMDSS). Moreover, the proposal follows the fifth step of the Reynolds et al. (2016) roadmap, which classifies monitoring into different types and offers guidelines to conceptual model developers. Specifically, the effectiveness monitoring is one of the types Reynolds et al. (2016) define. This type of monitoring focuses on the effects of management actions. It assesses the effect of specific policy implementation by explicitly documenting the response in the system and noting the degree to which desired outcomes are attained.

The following section summarizes theoretical references and divides them into three parts. The first part outlines monitoring as a module of a FMDSS and describes monitoring under such a perspective. The second part defines adaptive management, and the third part synthesizes the guidelines found in the literature on how to design a monitoring conceptual model.

The third section describes the proposed model that adheres to the previously summarized theoretical references. The fourth section shows the result of applying the proposed model in the Sao Paulo case. Final remarks sum up the experience and suggest some eventual improvements.

\section{Theoretical references}

2.1. Monitoring as a module of forest management decision support systems (DSS)

From the forest policy formulation perspective, Knowledge Management (KM) supported by information technology is needed to 
deal with the huge amount of data that describes the territory, forest silviculture activities, and production over time (McDill, 2014). Analysing the use of KM in the decision support system (DSS) that intends to monitor the environment, Cortés et al. (2001) point out that a DSS tool can maximize the performance of a process and minimize the negative impacts of faults.

KM, according to Plunkett (2001), is the conscious strategy of putting knowledge into action as a mean to increase organizational performance. Technologies that support KM are available and effective (Rauscher et al., 2007). The role of information technology (IT) is to store and to provide access to knowledge (Plunkett, 2001). KM uses technology to identify, create, structure, and share knowledge with the goal of improving decision-making (Tyndale, 2002). To increase performance and improve decision-making gradually, in each iteration of a planning process, computerized tools may be useful because of their ability to store, retrieve, display and organize knowledge (Hujala et al., 2013).

They emphasize that the effectiveness of an environmental DSS involves a "continuous intelligent monitoring system". Because of the significance of the decision impacts, environmental DSSs must allow knowledge-based decisions. Bagstad et al. (2013) analysed 17 ecosystem services DSS and found that there is a general need for more investments in organizing data from previous processes, sharing existing data, and improving the quality of input data. Researchers stressed the importance of $\mathrm{KM}$ in forest management processes in a collection of 80 lessons extracted from 31 cases in 10 different countries. Almost half of them had KM as a major theme in the group of concerns (Gordon et al., 2013). Authors (Vacik et al., 2013) also say that a KM base is the main output of a monitoring system because it is created upon a sequence on information, which are data treatment output and these data are gathered by a monitoring system.

McDill (2014) and other authors (Vacik and Lexer, 2013) consider the monitoring process to be an important part of the planning process. That is, to be completed, a planning process must include the monitoring phase (Fig. 1). If the monitoring and planning processes are integrated, the information used in supporting a decision can be compared to the achieved outcome, which enables better decision-making in the future (Rauscher et al., 2007). It is important to highlight the fact that the Enterprise Resource Planning systems used in larger enterprises have been being built to integrate the planning and monitoring processes since the early 1990s (Blount et al., 2016) and are still extensively being used all over the world (Dechow and Mouritsen, 2005; Gholamzadeh Chofreh et al., 2016; Park and Jeong, 2013; Saade and Nijher, 2016).

A proper KM tool supported by information technology responds to questions regarding who produces and how much, which regions best suit each kind of production, and what the social, economic, and ethical consequences of a reduction or an increase in forest production may be (Rauscher et al., 2007). The answers to those questions could guide policy makers in their decisions. However, this is only possible if the parameters used in policy formulations are based on that information. Some authors remark that managers and decision makers should not be overwhelmed by data because what they need is not "more information" but values, priorities, and clarity about preferences (Ekbia and
Reynolds, 2007; McElroy, 2000; Vacik et al., 2013). Therefore, data about the process must be treated and organized in a useful manner to forest policymakers and managers.

In addition, forest policymakers usually face uncertainties regarding future environmental conditions, social demands, changing trends, and projected performances of markets for forest products (Rist et al., 2016; Vacik and Lexer, 2013). Therefore, adaptive management has been viewed as a very promising conceptual framework for defining forest management and policy formulations (Rist et al., 2016; Vacik and Lexer, 2013). Adaptive management is a continuing cycle of four activities, namely planning, implementation, monitoring, and evaluation, in which monitoring and data interpretation play essential parts in the whole planning cycle (Dickinson et al., 2016).

As planning cycles evolve, a tool to monitor performance indicators is needed to allow forest managers to compare outcomes among cycles. To achieve the improving process, all the verifiers of the indicators have to be well known and registered (McDill, 2014). According to Meng and Minogue (2011), practitioners consider monitoring models based on key performance indicators (KPI) are very effective systems. KPIs link performance with objectives and processes because the objective of the project is expressed in terms of values of indicators to be achieved (Shohet and Nobili, 2016).

The need of having a supportive monitoring component leads to the need for an applicable set of models to guide the development and integration into a modern Forest Management DSS. This need motivated the authors to conduct this research. Even though many authors agree that data from the monitoring process takes part in the forest planning process, the forest academia has focused on the planning part of the problem. Planning parameters, efficient methods of solving planning problems, and stakeholder involvement have received the largest share of attention from forestry academia over the last 50 years (Borges et al., 2014; Eriksson et al., 2014, 2013; Gordon et al., 2013; Nobre et al., 2016). In terms of forest planning, the modelling of a planning problem usually involves some sort of scheduling or assignment in the future. Monitoring processes also need models, reliable methods (Thompson, 2014), and the involvement of stakeholders to represent forest realities accurately.

Once defined, the outcomes of a plan have to be monitored by means of performance indicators that were specially defined to measure how close the managed forest is to reaching expected goals and whether the planned interventions have been effective. Unfortunately, and probably due to the spatial scale of most forest problems, technological limitations, and the large amounts of data needed, the detailed integration and modelling of the monitoring phase is not usually considered when dealing with forest policy or management planning formulations (Dickinson et al., 2016).

As already pointed out, comprehensive Environmental DSS and Ecosystem Services DSS should have as one of their building blocks a reliable monitoring model. That also applies to an environmental and forest policy DSS. Under the perspective of a DSS conceptual frame we are presenting a monitoring module that composes an FMDSS. And this module is carefully designed to improve planning iterations incrementally.

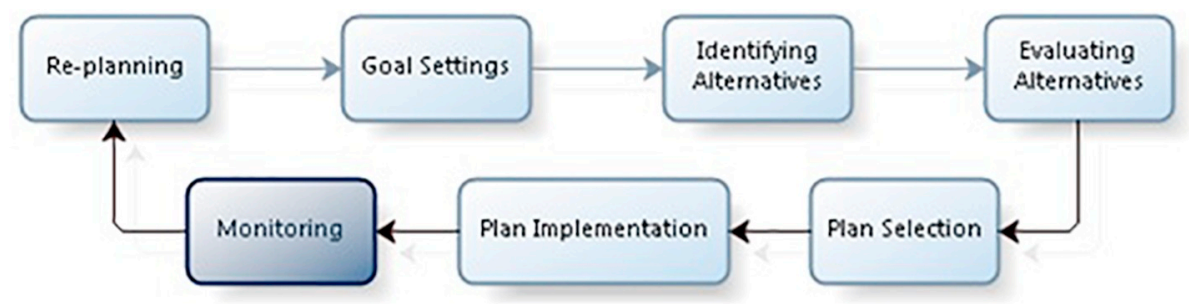

Fig. 1. Planning process (McDill, 2014). 


\subsection{Monitoring embedded in adaptive management frameworks}

In the previous sections, we could see that the purpose of monitoring is to generate useful information to answer the motivating questions from many different perspectives. Adaptive management concepts go beyond and insert the monitoring in an iterative decisionmaking cycle (Reynolds et al., 2016). It goes beyond improving planning iterations and includes a quantitative learning process to combine (i) effectiveness monitoring and (ii) predictive models quantifying the expected outcomes.

The adaptive management cycle has critical trigger points to ensure that corrective actions will be taken if any restoration targets are not being achieved (Viani et al., 2017). If environmental uncertainty is a major concern, monitoring under adaptive management should, ideally, lead to learning. Therefore, the adaptive management means midcourse corrections and large-scale changes in management direction (Gatica-Saavedra et al., 2017; Durigan and Ramos, 2013) based on knowledge gained from monitoring.

According to Reynolds et al. (2016), for monitoring associated with management actions, the updated models inform the next cycle of management. Consequently, the system model is refined by integrating the new observations into the quantitative model.

However, to be embedded in an adaptive management framework, a monitoring system requires a limited number of indicators that are repeatable, sensitive to change, and affordable (White et al., 2017). The choice of suitable ecological indicators is a challenge for monitoring ecosystem quality. According to Durigan et al. (2016) indicators should be easy to apply and, in the case of forest restoration, they should represent the gradual recovery of biodiversity, relevant ecological processes, and ecosystem services resulting of interventions.

As an example, Sao Paulo State developed a protocol to evaluate restoration success which requires only three ecological indicators: (a) native vegetation ground cover; (b) density of native plants spontaneously regenerating; and (c) number of spontaneously regenerating native plant species (Chaves et al., 2015; Viani et al., 2017).

\subsection{Requirements of a forest restoration monitoring conceptual model}

A monitoring model comprises (i) a process to gather data, information, or knowledge related to the facts of interest; (ii) a method to store and transform those data into information; and (iii) routines to interpret trends and produce outcomes (Bolloju et al., 2002). Due to the components of a model, databases have become valuable assets to any organization (Tyndale, 2002) mainly because of important improvements in information technology that have allowed the processing of new types of data, such as spatial, audio, and video data and the efficient processing of large database management applications. The observed improvements are even more noteworthy in forest management problems dealing with large-scale spatial constraints and operations occurring simultaneously in many isolated places.

The more complex the demands from the policies are and the more diverse the expectations of various user groups become, the greater the complexity of the models designed for use in DSS is (Vacik and Lexer, 2013). The complexity of the models requires parameters that represent reality, and the aim of a monitoring model is to gather together data and interpret them to create knowledge about the process. New knowledge about the forest process may become available if the system is correctly used, and this knowledge should result in new goals and revised parameters. This is precisely the aim of a monitoring component of a DSS: guaranteeing the knowledge expansion (Bolloju et al., 2002). At each cycle, the result of the evaluation activity gives feedback on the planning activity so that adaptive learning can take place (Vacik and Lexer, 2013).

By doing a search in the ISI's Web of Science for publications from the last five years on forestry and environmental science issues through articles and reviews using the keyword "forest monitoring," we found
35 papers with forest monitoring as the focus. Of these, 22 related to inventory modelling, growing, or biomass measurement, and 10 strengthened the importance of having data integration, at least among a sequence of measurements. The other 13 are related to land use, deforestation, and other environmental issues; and 7 reinforce the integration of other monitoring systems. Only one of these articles declares that the monitoring system would "facilitate better management plans." Even though all of them describe how they transform measured data into information on biomass growing or stock and land use, none of them is related to silviculture activities or costs control.

It seems, from this recent forestry publication presented in the last paragraph, that the usual concept of the monitoring means forest inventory and land use analysis. However, in general business, monitoring systems and control systems are related not only to productivity but also to control costs and activities related to productivity to produce better plan parameters (Jannuzzi et al., 2014).

Moreover, when it comes to ecosystem restoration, the focus is changing from forest structure and forest composition to restoring ecosystem processes. First, the emphasis was the return of structure (e.g., nutrients and selected plant species) rather than the repair of processes (e.g., hydrology, nutrient cycling, and energy capture). Second, the focus was on specific sites without considering the landscape context. Third, the concept was a "restore" program at the completion rather than the beginning of natural repair processes. A focus on returning structural components to functionally damaged ecosystems does not necessarily lead to the development of self-repairing ecosystems (Whisenant, 1999).

Therefore, the change from "forest monitoring" to "ecosystem monitoring" is a forest restoration requirement. The aim of a forest plantation is no longer an establishment of a production forest but a reestablishment of ecosystem processes (Durigan et al., 2016; Whisenant, 1999; Durigan and Ramos, 2013; Chaves et al., 2015; Albert et al., 2015; Gatica-Saavedra et al., 2017; Bodini, 2012; Reynolds et al., 2016; Ocampo-Melgar et al., 2016).

According to the literature, a conceptual monitoring model is defined as the intellectual foundation upon which a monitoring program rests as it makes the connection between system drivers (including management actions) and the fundamental objectives explicit, thus helping clarify exactly what should be monitored (Reynolds et al., 2016).

And some requirements are essential to a conceptual model. It:

- should consider the activities or interventions, and their relationships to the fundamental objective (Reynolds et al., 2016);

- should clarify the main types of uncertainties associated with management decision making such as (i) environmental variation inherent stochastic variation in environmental factors; (ii) partial controllability — imprecise application of management actions; (iii) partial observability - imprecise measurement of the system; and (iv) structural uncertainty - lack of understanding about relationships between system state and drivers, e.g., uncertainty in defining the model itself (Reynolds et al., 2016). The model should allow the monitoring program to control and/or reduce each of them;

- should allow information be presented in multiple ways to address the needs of different stakeholders and translated into a userfriendly decision support tools (Albert et al., 2015; Reynolds et al., 2016);

- should be a systemic model to be applied as conceptual bases and should represent the real systems (Bodini, 2012);

- a data interpretation component must be integrative; thus, model applications can be used profitably to attain a strategy of predictive monitoring. A system can be predictive only if planning or potential policies could be translated into new structural configurations of flows of activities (Bodini, 2012). 
Table 1

Land distribution in state of São Paulo.

\begin{tabular}{|c|c|c|c|c|c|c|}
\hline Area classes in hectares & {$[0,20]$} & {$[20,50]$} & {$[50,100]$} & {$[100,200]$} & {$[200+]$} & Total \\
\hline Number of properties in each area class & 174.352 & 77.720 & 32.888 & 19.722 & 19.640 & 324.322 \\
\hline Total area per Class (ha) & 1.743 .520 & 2.720 .200 & 2.466 .600 & 2.958 .300 & 10.571 .695 & 20.460 .315 \\
\hline
\end{tabular}

Table 2

List of policies.

\begin{tabular}{|c|c|}
\hline Group of policies & Policy \\
\hline \multicolumn{2}{|l|}{ 1: Regulations } \\
\hline Priority Areas & $\begin{array}{l}\text { Create areas according to the state priorities, like water supply, biodiversity distribution, and soil protection urgencies. } \\
\text { Through regulations, facilitate the restoration on those areas. }\end{array}$ \\
\hline Regulation Adjustments & Adjust all it is needed to promote restoration, number of species, restoration rules, and performance indicators to control. \\
\hline \multicolumn{2}{|l|}{ 2: Technical Assistance } \\
\hline Technical Recommendation & Encourage the state research institutes and consulting companies to study native species silviculture to find: \\
\hline & $\begin{array}{l}\text { - Suitable species to the state and their correct combination } \\
\text { - Species mix with economic return. } \\
\text { - Species distribution in the area to allow economic exploitation. } \\
\text { Training program to technical assistance public staff and amplifying the tech team through public-private partnership (PPP). }\end{array}$ \\
\hline Processes support & $\begin{array}{l}\text { Develop system to do the recommendation to the entire state. } \\
\text { Develop web-portal to publish the technical recommendations. } \\
\text { Develop monitoring system to feed planning systems. } \\
\text { Integrate the recommendation web-portal to the State Environmental Control System (SIGAM) already developed. }\end{array}$ \\
\hline Demonstration units & Research areas in several regions to demonstrate silviculture techniques: private and public land. \\
\hline \multicolumn{2}{|l|}{ 3: Infra-Structure } \\
\hline Funding & Negotiate with funding institutions. \\
\hline Forestry-base Industry clusters & Finding priority micro-regions to incentive forestry-base Industry clusters. \\
\hline Continuous research & Institutional agreements and research priorities to the state research. \\
\hline
\end{tabular}

\section{Methodology}

The goal is to develop a conceptual model that represents forest restoration monitoring processes that effectively measures the attainment of desirable outcomes. The São Paulo Forest Restoration Program is the case study that provides variables and processes to support the development of the conceptual model. Section 3.1 describes the São Paulo Restoration Program, and Section 3.2. describes the methodology used to develop the conceptual model.

\subsection{Case study - a forest restoration program in Brazil}

In this sub-section, a large forest restoration program is presented, in which monitoring takes an essential role to guarantee the success of the initiative. It is an appropriate case study sufficiently extensive, diverse and real to allow and test the generalization of the conceptual model proposed in this work.

The Brazilian Federal Law 2012/12651 determines that every rural private property has to set aside from 20 to $80 \%$ percent of its total area for forest management. This area is legally defined under the regulation as Legal Reserve (LR), and its aim is to ensure some economic and sustainable use of the rural property's natural resources and simultaneously promote its biodiversity conservation. The delimitation of the LR area is set forth in articles 12 and 13 of the law. Property owners have to plant only native forest species to compose the vegetation cover in the LR area.

The mandatory percentage of the total area on rural properties in the state of São Paulo to be maintained as LR is $20 \%$ (Zakia and Pinto, 2014). Most of the rural properties in the state do not have enough vegetation to fulfil this obligation. For these cases, the law establishes that the property owner must conduct some form of induced restoration, natural regeneration, or a combination of both until $20 \%$ of the property is covered with a legally reserved forested area (Zakia and Pinto, 2014). The LR area can be used for commercial purposes subject to some constraints monitored by key indicators established by state regulations.

The restoration of LR areas with Brazilian native tree species for commercial purposes is still incipient in the country. There is a lack of silvicultural techniques and information, and the uncertainty about markets for forest products and services is high (Zakia, 2013). These problems make proper economic evaluations very difficult and inhibit the supply and demand of adequate credit lines.

In the state of São Paulo, a restoration target was set to reach 300,000 ha in the next ten years (Barretto and Assunção, 2015). There are 20 million hectares in the hands of private farm owners, and the legal reserve deficit is estimated at 1,7 million hectares (Barretto and Assunção, 2015). Half of the area is in hands of 19,000 property owners, and the other half has 304,000 land units. The São Paulo State Department of Environment (SMA) expects that 30,000 to 40,000 landowners will present LR forest restoration projects to be analysed and approved during the upcoming years (Table 1).

Therefore, a new set of policies has been planned to mitigate eventual barriers that prevent landowners in this state from restoring their LR based in three fundaments: regulations, technical assistance, and infrastructure. Table 2 shows the set of policies per fundament. The São Paulo State Department of Environment (SMA) leads a mobilization of research institutes, universities, NGOs, and consulting companies to support the development and implementation of the new policies.

Many of these policies are in the implementation phase, and restoration has already begun. In Fundament 2, a "Legal Reserve" technical recommendation module has already been developed. This system is integrated into other systems that control licensing processes and the general registration of a property named "SIGAM - State Environmental Control System". 2

The set of policies listed essentially relies on the existence of a DSS named "Restoration Scenario Simulator". This tool determines all

\footnotetext{
${ }^{2}$ http://www.sigam.ambiente.sp.gov.br/.
} 
Table 3

Simulator database overview.

\begin{tabular}{|c|c|c|}
\hline Data type & Quantity & Data available, used by the simulator \\
\hline Number of property units & 324.000 & Maps \\
\hline Number of municipalities & 646 & $\begin{array}{l}\text { Maps, total area, priority area, land } \\
\text { PRICES } \\
\text { Climate data as temperatures, rain, } \\
\text { evapotranspiration etc. }\end{array}$ \\
\hline Phito-ecology units & 1597 & Maps, area, species adaptation \\
\hline Species & 250 & $\begin{array}{l}\text { Wood technical data, growth models, } \\
\text { taper models, BDH distribution models, } \\
\text { etc. } \\
\text { Species combination rules }\end{array}$ \\
\hline Wood products & 4 & Diameters, prices, markets \\
\hline Non wood products & 10 & Production curves, prices \\
\hline Silviculture operations & 50 & $\begin{array}{l}\text { Costs, inputs, labour hours, machinery } \\
\text { needed, etc. }\end{array}$ \\
\hline Insurance data & 1 & Interest rates, payment conditions, etc. \\
\hline Funding options & 20 & Interest rates, payment conditions, etc. \\
\hline Available nurseries & 208 & $\begin{array}{l}\text { Location, capacity, seedlings of each } \\
\text { species }\end{array}$ \\
\hline Available sawmills & 156 & Location, capacity \\
\hline $\begin{array}{l}\text { Number of tables in the } \\
\text { database }\end{array}$ & 80 & \\
\hline
\end{tabular}

possible alternatives of forest restoration available to each landowner depending on where the property is located. This DSS supports the policy formulation as it turns possible the simulation of forest restoration alternatives under different hypothesis.

The "Restoration Scenario Simulator" needs a large set of parameters to allow the simulations. A group of researchers, mobilized by SMA, from different knowledge areas carefully prepared these parameters. They are based on research data and a few restoration experiences we have in the country. All of them must be updated as soon as we have data from reality to support it.

A monitoring system is under development to complete the knowledge they need to update the parameters and support the entire restoration process (Rodrigues et al., 2013). The aim of the system is to gather data, and interpret them to (i) get feedback for the Legal Reserve Technical Recommendation Module and (ii) recommend adaptive actions (Adaptive Management System). In addition, the state needs to verify the effectiveness of the plan to adjust the policies (Table 3).

The monitoring model in the case study aims to check what has been actually done and verify whether forest restoration policies are stimulating changes and how effectively they have promoted forest restoration. The monitoring parameters will be iteratively recalculated to set new scenarios for the analysis of the subsequent cycles predicted in the environmental and forest policy DSS and to prescribe the need for policy revisions.

\subsection{The fundamental components of the model}

Fundamentally, the conceptual model is developed following an action learning approach. The action learning approach was idealized by Professor Reginald Revans during the 1940s (Revans, 2014). According to Waddill and Marquardt (2003), who conducted an extensive review of the theme, the power of action learning is its wide-ranging application to both learning and action. Practitioners and theorists from diverse disciplines, including science, embrace its practical effectiveness.

(L):

Revans (2014) proposed a very basic equation to express learning

$\mathrm{L}=\mathrm{P}+\mathrm{Q}$

where $\mathrm{P}$ is the acquisition of programmed knowledge and $\mathrm{Q}$ is insightful questions.

Action learning offers a useful starting point to treat problems in the real world when no solutions have yet been envisioned (Revans, 2014).

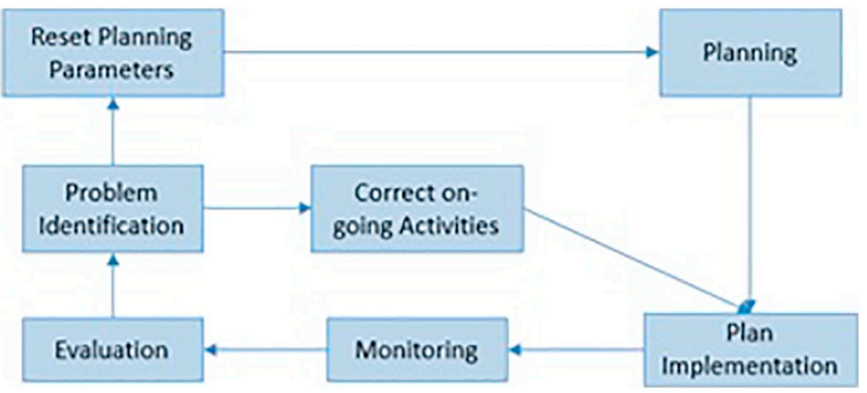

Fig. 2. Essentials of the case study.

Action learning recognizes that in the absence of any insight $(Q)$, programmed knowledge (P) is not sufficient to solve the described problem. Therefore, good propositions cannot be applied to the problem until insightful questions are asked. That is to say, $\mathrm{P}$ is necessary but, in the absence of $Q$, is not sufficient.

In the context of this work, the theoretical content described in Section 2 could be referred to as programmed or predisposing knowledge (P). The insightful questions (Q) could be stated as (i) 'what information is essential and sufficient to monitor?' And (ii) 'how is the monitoring process organized to become effective?' During the designing process, we detailed the original question about data to define precisely what variables we should measure to calculate the ecological indicators. Similarly, we detailed the question about processes to determine when, why, and how each variable would be measured.

The action of learning fundamental concept provides the foundations for building the conceptual model presented in this work. The development process guarantees the building of a conceptual model that is simultaneously useful for the case study and generalization.

Fig. 2 shows the main forest restoration phases predicted in the case study. It essentially resembles the planning process depicted by McDill (2014) in Fig. 1, except for the need to detour after the monitoring evaluation component to either correct on-going activities or reset planning parameters.

The presentation of the conceptual model shows fundamental components, with their corresponding breakdowns and generalization. For the sake of clarity, the breakdown of each fundamental component splits into two parts, planning and monitoring, with the precise identification of the many planning actions and events involved.

\subsubsection{Planning and monitoring processes}

Fig. 3 shows a diagram for the policy implementation of the case study. The monitoring process gathers data from the fundraising phase until final operational activities in the field. The system translates data received from the inspection team and other controlling processes into interpreted outputs that are then stored in a knowledge base.

The next step involves evaluation of the monitoring iteration. The evaluation checks for (i) goal achievement, (ii) acceptability of intermediate results, and (iii) adherence to recommendations by landowners. The assessment of the goals triggers the reformulation of the policies. Plantation inspection triggers the review of technical recommendations, and intermediate results trigger the "Adaptive Management System" to recover or improve actual plantations. These actions are identified as "Evaluate the monitoring iteration" in Fig. 3.

The success of this first phase relies on:

(i) organized gathering of each iteration data,

(ii) adequate interpretation of data gathered,

(iii) prioritization of resources to trigger immediate adaptive management action,

(iv) continuous revision and reformulation of policies for next planning cycle. 


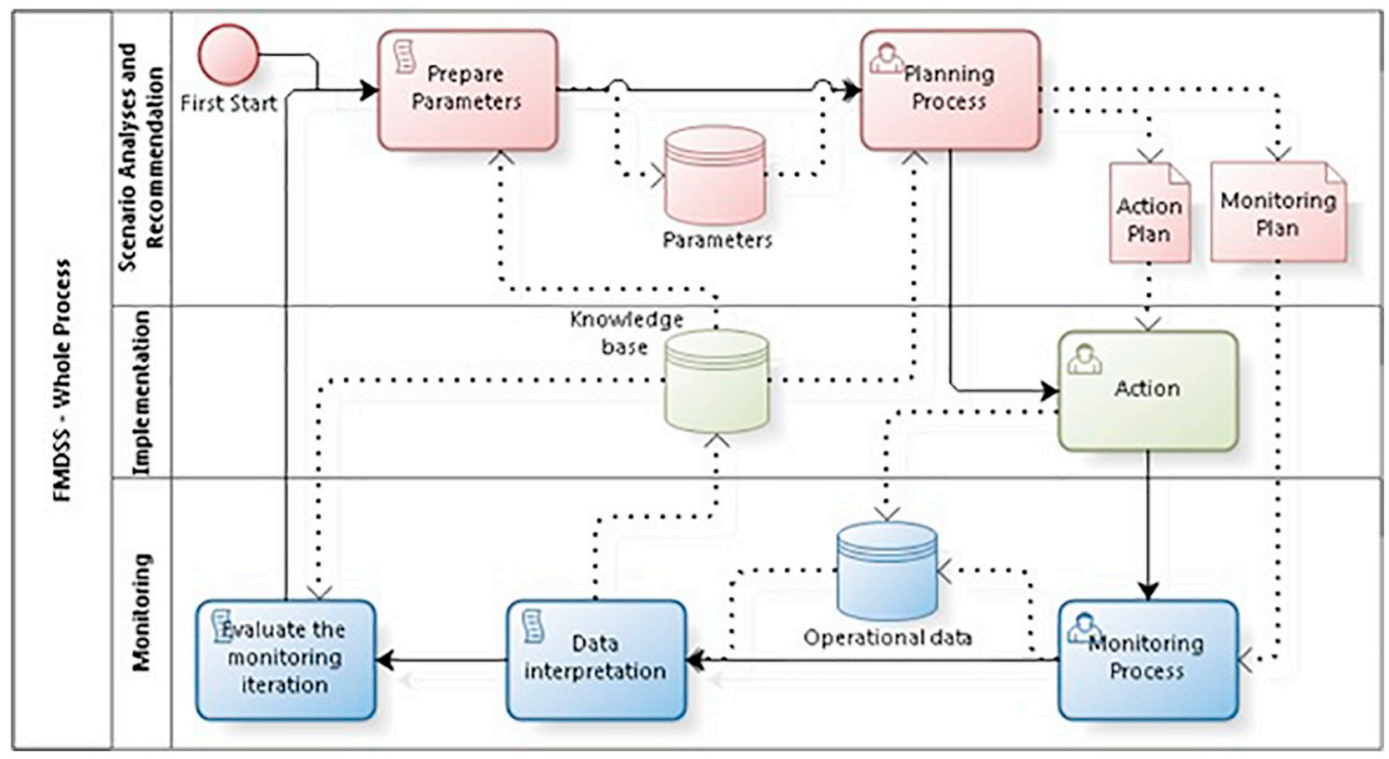

Fig. 3. Planning and Monitoring processes.

At this stage, the main stakeholders are individuals involved in the process as system developers, system users (landowners and technical assistants) and forest experts.

\subsubsection{Breakdown of the planning component}

A breakdown of the planning component allows a proper design of an integrated monitoring. It is important to see in Fig. 4 that there are two distinct subdivisions in the planning process separated by an intermediate sub-process, "Policies: review guidelines." The first subdivision regards the "scenario analyses" and the second relates to "revisions of a set of policies".

The first subdivision, "scenario analyses" has two important components before the first simulation cycle:

(i) Gather new parameters. Many of them come from internal systems, and others come from external sources.

(ii) Update parameters, such as priority areas, possible costs, prices, market information, and production models (update production equations using updated data from monitoring process).

The intermediate sub process, "Policies: Review Guidelines," focuses on results and reports coming from the critical IT-based sub process, "Scenario Analyses" and "Simulation". Policy makers reach mutual consensus on guidelines for the next steps during public hearings and workshops.

In the first iteration of planning, parameters come from a database organized by the best estimations the experts' team of the State Department of Environment could get. From the second iteration on, the database is updated accordingly to adjustments produced by the monitoring module. In the next section, a breakdown of the monitoring module is presented to provide the details that will guarantee the proper updating of the database.

The second subdivision, "revisions of a set of policies", comprises the policies' definitions, which are independent of each other, even though the same parameters are used to support all of them. From what we observed during research, typically, in the region, those definitions are prepared in consensus meetings and tend to be not based on the information. From the first iteration on, data will start constituting a first knowledge base that must be done according to the specifications to gain the confidence of São Paulo State leadership.

\subsubsection{Breakdown of the monitoring component}

In the case study, landowners are required by law to perform a sequence of steps to unlock the restoration process itself and its operations. Firstly, the landowner has to register the property with the "CAR - Cadastro Ambiental Rural" (Rural and Environment Register), in which a geo-referenced map of its property is required. The landowner declares the Legal Reserve (LR) area portion inside the boundaries of the property.

Secondly, landowners have to access the - Legal Reserve Technical Recommendation Module to perform a small series of choices, according to their preferences, and to generate the pre-approved restoration project. Landowners can make adjustments in this project according to their local needs and submit them for SMA approval.

Once approved, a restoration project in accordance with the nature of the landowner's property is ready to be issued. Called PRA Environment Restoration Plan, this project complies with Brazilian laws $12.651 / 12$ and $7.830 / 12$ which will be submitted with the support of another SIGAM module.

Thirdly, the landowner has to seek alternatives to fund the operation. Landowners can use their funds or request them from state or private banks. No IT module supports this subprocess completely.

Finally, according to the PRA - Environment Restoration Plan module, a report gives a schedule of restoration to produce an "Inspection Plan" that meets the inspection teams' availability. The inspection team visits the properties and measures what was planned to be measured.

The subprocess, "Trigger Report," produces reports describing how landowners performed each action (Fig. 5). The answers from landowners about the reasons for non-performed actions can come through by sample gathering or by census according to the available resources. After reading the response, the Data-Treatment subprocess must process and save them in a structured format in a knowledge base.

The "Inspect area" subprocess should produce a diagnostic of each land property according to at least KPI (key performance indicators) required by forest regulations, such as (i) sapling quality, (ii) the amount of sapling, and (iii) basal area. Additionally, the technical support team will measure more variables to feed the rule calculations of the adaptive management, such as the sequence of silvicultural operations the landowners made and corresponded inputs they applied.

The rules are based on barriers the ecosystem must overcome to achieve the predefined levels of restoration (Durigan and Ramos, 2013; Rodrigues et al., 2013). For each set of values of the indicators, the 


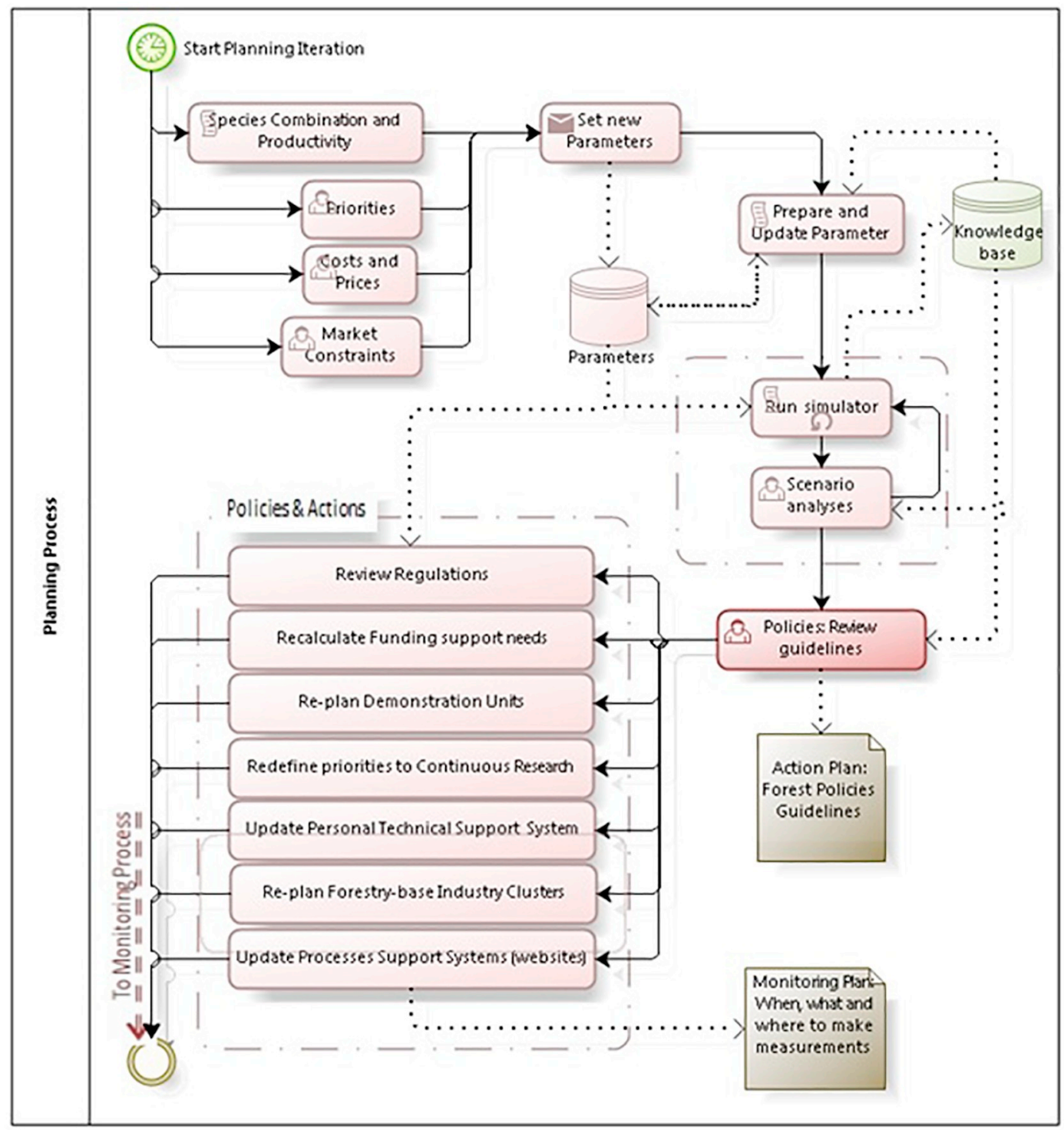

Fig. 4. Breakdown of the monitoring component.

system recommends one sequence of actions to correct the regeneration course. Table 4 contains some examples of these adaptive management rules.

From the "Report on funding" subprocess on, there are no IT resources to support the process. SMA is projecting the further modules of the system. In this first version of the monitoring application, the system will follow the rules and provide a recommendation. However, the system is not going to change the rules automatically according to the results because there is no enough knowledge to do it yet. It will be a user subprocess performed by local researchers to analyse the results and propose revisions to the rules.

Fig. 6 describes the details of the adaptive management subprocess showing how researchers follow and review rules. Each inspection of each land property, which happens in a monitoring iteration, admits an adaptive management subprocess. When it is completed, i.e., when all land properties are properly inspected in the actual iteration, the system is ready to check the goals.

According to the actual view of the policy makers, the main KPIs are as follows:

(i) the sum of the area implanted in the year;

(ii) the sum of the area stopped in each step of the process and the stop reasons;

(iii) the sum of the area has surpassed each barrier of restoration per age of planting;

(iv) an average of restoration performance indicators (basal area, the amount of sapling, and quality of sapling).

All ecological indicators should be available per region and other dimensions present in the knowledge base, including at least sub-regions, counties, municipalities, types of funding, and the technical support team. This information is going to be used to review the set of state policies as Fig. 5 demonstrates. Depending on which dimension group the available indicators is, policymakers can also have the effectiveness of (i) technical support teams, (ii) the funding process and (iii) IT resources used in the process.

\section{Results - a generalizable model}

The model described in the previous sections serve as a framework to conduct the monitoring component of the forest restoration program fostered by the government of the state of Sao Paulo in Brazil. To describe the generalizable model, we use some terms defined according to Table 5. 


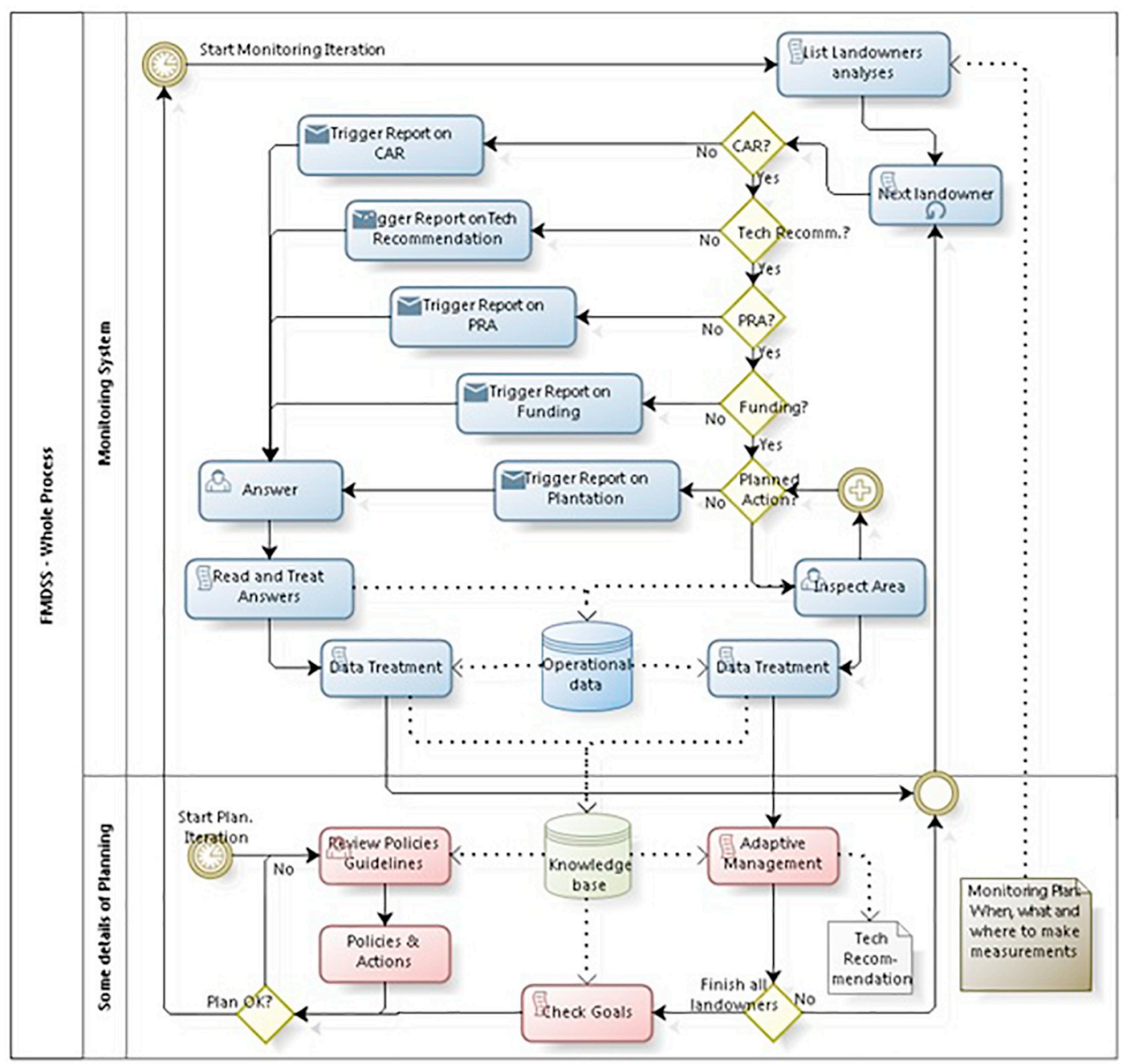

Fig. 5. Breakdown of the monitoring component.

We can describe the generalizable model (Fig. 7) by using previous definitions as follows:

Firstly, the system recovers all GeoUnits and separates the units in which status has changed since the last analysis. Each GeoUnit brings the information on which step of the whole forest process it has stopped. There are two types of steps:

(1) an operational step when a technical visit is needed;

(2) a report step when only a set of questions must be answered online or offline, entirely IT-supported or not.

If for a specific GeoUnit, the next step required is an operational one, the "Optimized Visiting Plan" process is triggered; if not, a reporting procedure for that step is triggered. A reporting procedure can be a query in other modules of the same system, or a query over external systems, even an email or a list of telephone calls or any other types of manual tasks. The aim of each reporting procedure is to report the status of each unit in a step that is being analysed.

In the side of operational steps, each visit will produce data that should be input into the database. On the other hand, a report step should produce an answer for each GeoUnit, which also should be input into the database. This data constitutes the "operational database". On both sides, the next step is "Data Treatment" to transform data into structured knowledge to further use as planning parameters.

In the operational side, after "Data Treatment", "Adaptive Management" is the next subprocess, which comprises a technical recommendation to correct the progress of the analysed GeoUnit, if needed. Treated visiting information and stored rules are the foundation for the recommendation.

When all units are analysed, the system can proceed to Policies Revisions. This subprocess cannot be fully automated, but IT tools can actively support it. Over the time, the data treatment process might be

Table 4

Examples of Adaptive Management: Atlantic Forest Restoration according to Zakia (2013).

\begin{tabular}{|c|c|c|}
\hline KPI - key performance indicators (2) & Verifiers: minimum values & Adaptive management \\
\hline Percentage of invasive grasses & $25 \%$ & Grass control (chemical or biological control depending on other KPI values) \\
\hline Invasive tree species & Absent & Invasive species control (mechanical methods) \\
\hline Invasive shrub species & Absent & Invasive species control (mechanical or chemical methods depending on other KPI values) \\
\hline Land cover with native species & $75 \%$ & Replantation \\
\hline tree species basal area $(\mathrm{DBH}>5 \mathrm{~cm}) 200 \mathrm{~m}^{2}$ plots & $18,75 \mathrm{~m}^{2}$ & Thinning or re-planting depending on other KPI values \\
\hline Tree species diversity & 20 & Enrichment or seeds bank transposition depending on others KPI values \\
\hline
\end{tabular}




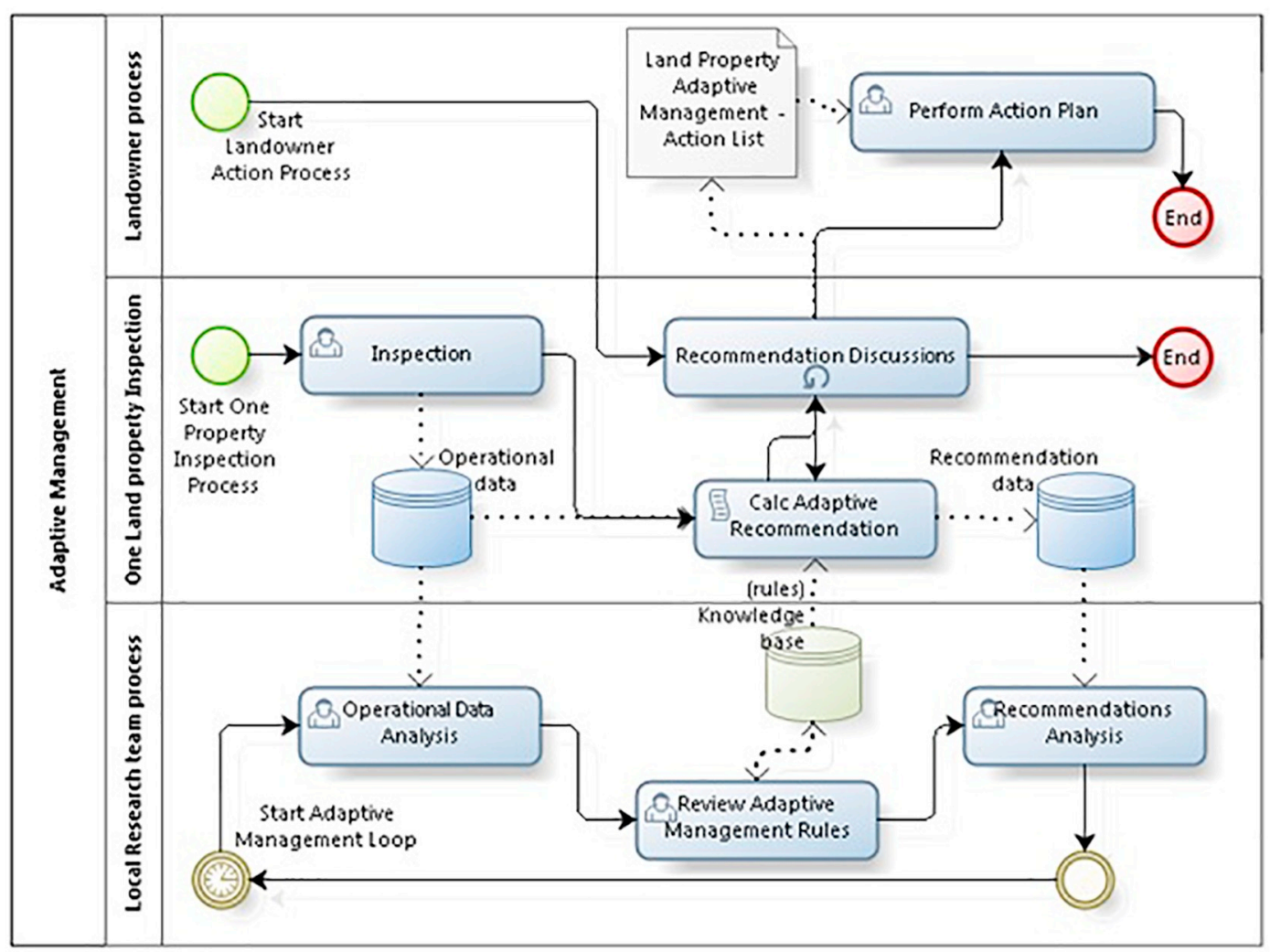

Fig. 6. Adaptive management.

improved based on experience. Data, after being treated, is transformed into information knowledge upon which Policies Revisions will be done.

\section{Discussion}

Throughout the design of the model process, we used a set of checkpoints extracted from the literature review and presented in the previous sections. In this section, we discuss whether the resulting model meets the recommendations claimed in the literature review.

The fundamental components (Fig. 2) and the breakdown of the planning component (Fig. 4) set the basis for the formulation of a generalizable model. The diagram for the breakdown of the planning component indicates that the planning parameters must come from the knowledge base. Accordingly, the diagram for the breakdown of the monitoring component (Fig. 5) shows that data derived from monitoring processes should be entered into the knowledge base only after it has been arranged and checked properly. This sequence guarantees that the policies can rely on real-world knowledge as recommended by Rist et al. (2016) and Vacik and Lexer (2013) (Table 6 - recommendation 01).

The breakdown of the monitoring component (Fig. 5) shows that the model considers which interventions have been implemented in each land unit (Reynolds et al., 2016). It is crucial to have interventions and correlated outcomes precisely registered for the purposes of adaptive management (Bodini, 2012). Hence, the system can suggest changes regarding technological recommendations for the next planning cycle (Bagstad et al., 2013; Hujala et al., 2013; Tyndale, 2002). Also, urgent actions to fix problems affecting the growth of the plantation can be triggered (Cortés et al., 2001; Durigan and Ramos, 2013; GaticaSaavedra et al., 2017; Plunkett, 2001) (Table 6 - recommendations 2, 3, 4, 5, and 6). However, fixing silvicultural operations of fast-growing species once plantations have been established in Brazilian restoration projects can be challenging. The effectiveness of the adaptive management approach will also depend on the allocation of sufficient amounts of resources.

It is important to emphasize that the knowledge base is a central entity in both the planning and monitoring processes (Dickinson et al., 2016; Ekbia and Reynolds, 2007; McElroy, 2000; Vacik et al., 2013). The two most critical activities in the whole process are data treatment, one of the activities pertaining to the monitoring component (Fig. 5), and prepare parameters, another activity in the planning component (Fig. 4), listed as recommendations 7 and 8 of a conceptual model (Table 6).

The continuity of the cycle, which guarantees the improvement of the forest operations, depends on the integration between monitoring

Table 5

Terms and definitions.

\begin{tabular}{|c|c|}
\hline Terms & Definitions \\
\hline Forest process & $\begin{array}{l}\text { A sequence of events related to forestry or the environment that happens in the field or an IT system context involving stakeholders, such as policy makers, IT } \\
\text { resources, technical teams, landowners, or researchers. }\end{array}$ \\
\hline Iteration & Each repetition of a piece of a process is called an "iteration," and the results of one iteration are used as the starting point for the next iteration. \\
\hline GeoUnit & $\begin{array}{l}\text { A forest process happens upon a set of forest geographic units - GeoUnits. This can be farms, regions, stands, watersheds and so forth. In our generalizable model, } \\
\text { we consider we have U units from } 1 \text { to u. }\end{array}$ \\
\hline Steps & $\begin{array}{l}\text { The responsibility for each unit should be to perform a sequence of different steps; this sequence constitutes an iteration. In our generalizable model, we consider } \\
\text { we have S steps, from } 1 \text { to s. }\end{array}$ \\
\hline
\end{tabular}




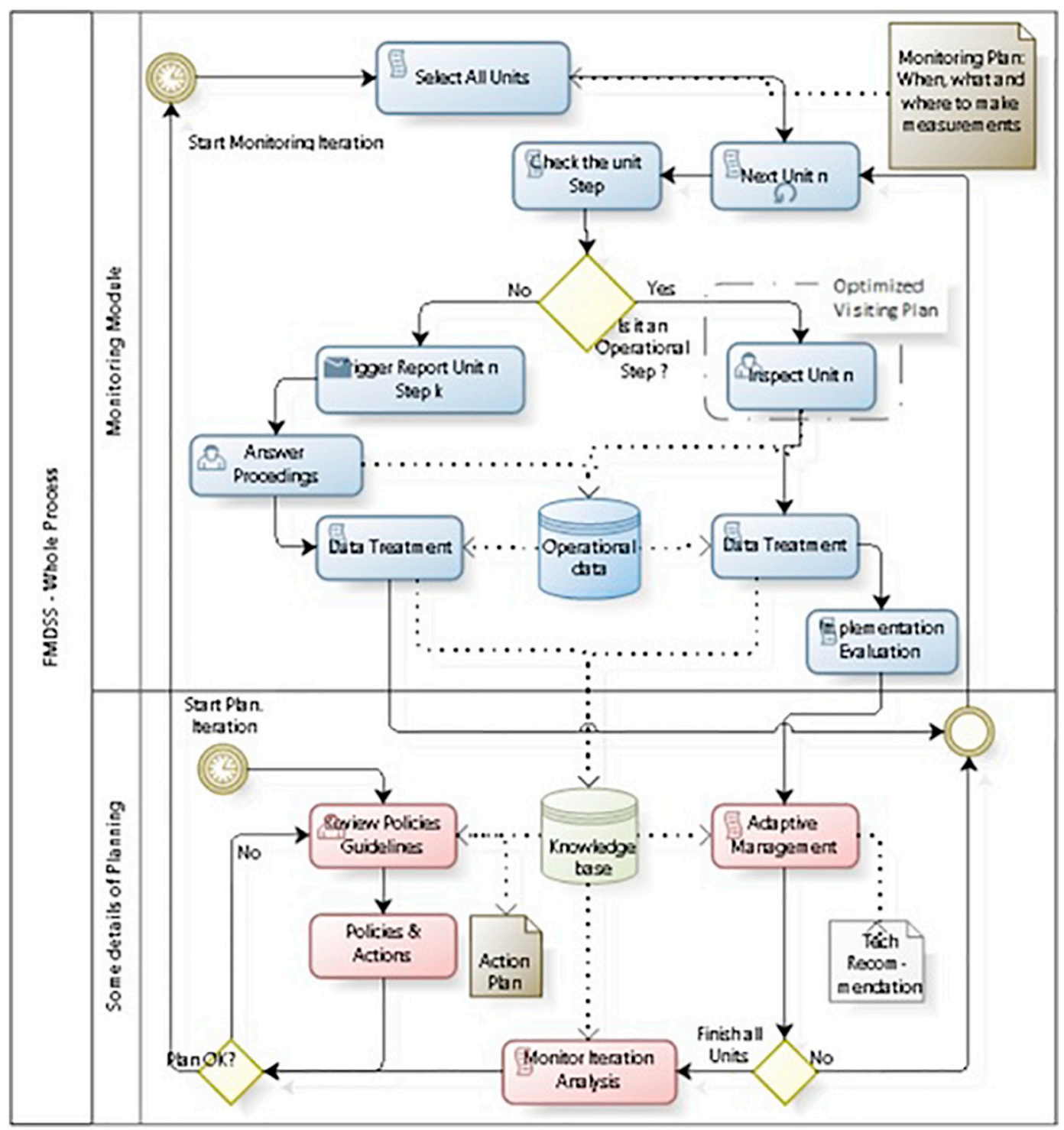

Fig. 7. Generalizable process model.

and planning. In the proposed conceptual model, integration is ensured if planning updates come from the monitoring process itself as the knowledge base evolves (Blount et al., 2016; McDill, 2014; Rauscher et al., 2007; Vacik and Lexer, 2013).

The inclusion of the monitoring component in the conceptual model became a principle proposed by Rauscher et al. (2007) and was embedded in a FMDSS following the guidelines established by Albert et al. (2015) and Reynolds et al. (2016). The resulting DSS allows decisionmakers to rely on a knowledge base supported by real-world information, which implements recommendations 1, 9, and 10 Table 6 as described by Rist et al. (2016) and Vacik and Lexer (2013).
Naturally, not all available knowledge becomes stored in the knowledge base, and there will always be non-internalized knowledge guiding decision-makers in different directions (Nemati et al., 2002). Additionally, in a forest restoration context, the long-term accumulation of contradictory knowledge can misguide the knowledge creation process. Therefore, the conceptual model proposed here emphasizes the need for a continuous update of the data treatment and parameters preparation rules.

Bodini (2012) recommends the development of FMDSS supported by information technologies (IT) tools. The case study considers the existence of $>40,000$ restoration projects, and the use of IT tools

Table 6

Checking points of literature recommendation.

01 Planning and Policies rely on knowledge

02 Consider activities or interventions

03 Data interpretation component must be integrative

04 Continuous intelligent monitoring

05 Can maximize the performance of a process and minimize the impacts of faults

06 Has critical trigger points to ensure that corrective actions

07 Organizing data from previous processes
Gathering knowledge during the monitoring process

9 Translated into a user-friendly DSS

10 Computerized tools can be developed

11 Systemic model that represents the real systems

12 Clarify the uncertainties

13 Has a limited number of indicators that are repeatable, sensitive to change, and affordable 
becomes the only viable way of dealing with a large amount of input data, the complexity of the data treatment, the territory extension, and the long duration of the project (Table 6 - recommendations 10 and 11).

When it comes to reducing uncertainties associated with the decision-making process, as required by Reynolds et al. (2016), we argue that our conceptual model overcomes this challenge by interpreting the results of previous management cycles and updating the knowledge base to reduce future uncertainties in the next management cycle (Table 6, recommendations 13 and 14). Furthermore, the inclusion of ecological indicators in the monitoring component proposed by Chaves et al. (2015) becomes a source of risk reduction and precautionary action.

The conceptual model described here is generalizable and applicable beyond the realms of FMDSS. Its development, as described here, reveals guidelines that can be followed when dealing with similar situations. Even though cases are always different one from another in some particularities, as stated by Rohde et al. (2016), the generalizable principles used to develop the conceptual model result in continuous intelligent monitoring processes that make the systems adaptable to apparently dissimilar situations.

As seen in the discussion above, each subprocess and each aspect imposes specific challenges, leading to situations where the development of information system projects still fails to deliver sufficient benefits (Rohde et al., 2016). Conceptual models that integrate adaptive planning and monitoring processes, supported by an auto-updatable knowledge base, mitigate the risk of such failures, especially when the comprehensive gathering of well-established references for the initial knowledge base is well conducted at the beginning.

\section{Conclusion}

This paper presents a generalizable conceptual model that builds upon an initial knowledge base that evolves "by learning." Two specific mechanisms that collect and treat data from ecological indicators in each of the two planning and monitoring component phases considerably reduce the design effort. Moreover, the design promotes the maintenance of an auto-updatable knowledge base that internalizes creativity into the planning and monitoring of integrated processes. The integration of the two main building blocks, planning, and monitoring, into a single conceptual model supported by a knowledge base that learns as it evolves expands the benefits of working with knowledge bases solely built upon scientific information. The result is a conceptual model that incorporates many of the desirable characteristics published by experts in the related literature.

An intelligent monitoring process is achievable as the continuously updatable knowledge base adapts itself, maximizing performance, minimizing the negative impacts of failures, and gradually increasing the beneficial effects of the outcomes. We describe the application of the generalizable conceptual model in a forest restoration case study that creates an FMDSS. Basically, the DSS relies on a continuous improvement loop: (i) read and treat data from processes; (ii) transform data into knowledge by checking indicators and updating the knowledge base; (iii) use knowledge to update policy guidelines; (iv) update recommendations; and (v) read and treat data from processes again.

The development and implementation of the monitoring component of the conceptual model in the case study is a broad and multifaceted project still under development. Currently, the implementation of the monitoring component is being expanded gradually by IT resources that will allow for the participation of the many stakeholders, including landowners, agricultural extension professionals, and others. Limited to a region in the state of São Paulo, the exercise is being conducted with the expectation to have its use expanded to the rest of the state and even to other states in Brazil. Similar initiatives are following the experience in the state of São Paulo and creating their versions of the same principles and conceptual model, adapting their original knowledge base.

The on-going tests of the proposed generalizable model in other case studies and situations are triggering further research and evaluations. As prescribed by the process itself, these tests are producing new references potentially useful for the improvement of the current knowledge base used by the conceptual model in the state of São Paulo. Given the adaptive nature of the proposed conceptual model and its high level of resilience, the expectation is that the system will survive the implementation phase and become an efficient way to help the Brazilian government achieve its forest restoration targets and commitments.

\section{Acknowledgments}

The first author gratefully acknowledges the support of $\mathrm{CNPq}$ Brazilian National Research Council - scholarship 202017/2015-0. We also acknowledge support from COST Action FP1207 - Orchestrating forest-related policy analysis in Europe (ORCHESTRA), namely through the funding of the Short Term Scientific Mission (STSM) of the first author. Additionally, this research was partially funding by the European Union's H2020 research and innovation programme under the Marie Sklodowska-Curie grant agreement No. 691149 - SuFoRun.

\section{References}

Albert, C., Galler, C., Hermes, J., Neuendorf, F., Von Haaren, C., Lovett, A.A., 2015 Applying ecosystem services indicators in landscape planning and management: the ES- in-planning framework. Ecol. Indic. 61, 100-113. http://dx.doi.org/10.1016/j. ecolind.2015.03.029.

Bagstad, K.J., Semmens, D.J., Waage, S., Winthrop, R., 2013. A comparative assessment of decision-support tools for ecosystem services quantification and valuation. Ecosyst. Serv. 5, 27-39. http://dx.doi.org/10.1016/j.ecoser.2013.07.004.

Barretto, A.G.O.P., Assunção, A.L.C., 2015. Reserva legal no estado de São Paulo: situação atual e possibilidades de adequacão para as propriedades agrícolas. São Paulo.

Benini, R., de Adeodato, S.M., 2017. Economia da restauração florestal.

Blount, Y., Abedin, B., Vatanasakdakul, S., 2016. Integrating enterprise resource planning (SAP) in the accounting curriculum: a systematic literature review and case study. Acc. Educ. 25, 185-202.

Bodini, A., 2012. Building a systemic environmental monitoring and indicators for sustainability: what has the ecological network approach to offer? Ecol. Indic. 15, 140-148. http://dx.doi.org/10.1016/j.ecolind.2011.09.032.

Bolloju, N., Khalifa, M., Turban, E., 2002. Integrating knowledge management into enterprise environments for the next generation decision support. Decis. Support Syst. Decis. Support Syst. Dir. Nest Decad. 33, 163-176. http://dx.doi.org/10.1016/ S0167-9236(01)00142-7.

Borges, J.G., Nordström, E.M., Garcia-Gonzalo, J., Hujala, T., Trasobares, A., 2014. Computer-Based Tools for Supporting Forest Management. The Experience and the Expertise World-Wide. Department of Forest Resource Management, Swedish University of Agricultural Sciences, Umea.

Chaves, R.B., Durigan, G., Brancalion, P.H.S., Aronson, J., 2015. On the need of legal frameworks for assessing restoration projects success: new perspectives from Sao Paulo state (Brazil). Restor. Ecol. 754-759.

Cortés, U., Sànchez-Marrè, M., Sangüesa, R., Comas, J., R.-Roda, I., Poch, M., Riaño, D., 2001. Knowledge management in environmental decision support systems. AI Commun. 14, 3.

Dechow, N., Mouritsen, J., 2005. Enterprise resource planning systems, management control and the quest for integration. Acc. Organ. Soc. 30, 691-733. http://dx.doi. org/10.1016/j.aos.2004.11.004.

Dickinson, Y., Pelz, K., Giles, E., Howie, J., 2016. Have we been successful? Monitoring horizontal forest complexity for forest restoration projects. Restor. Ecol. 24, 8-17. http://dx.doi.org/10.1111/rec.12291.

Durigan, G., Ramos, V.S., 2013. Manejo Adaptativo: primeiras experiências na Restauração de Ecossistemas.

Durigan, G., Suganuma, M.S., Galv, C., 2016. Valores esperados para atributos de florestas ripárias em restauração em diferentes idades Expected values for attributes of riparian forests undergoing restoration at different ages. Sci. For. 463-474.

Ekbia, H.R., Reynolds, K.M., 2007. Decision support for sustainable forestry: enhancing the basic rational model. In: Sustainable Forestry: From Monitoring and Modelling to Knowledge Management and Policy Science, pp. 497-514.

Eriksson, L.O., Wahlberg, O., Nilsson, M., 2013. Questioning the contemporary forest planning paradigm: making use of local knowledge. Scand. J. For. Res. 1-15. http:// dx.doi.org/10.1080/02827581.2013.834960.

Eriksson, L.O., Garcia-Gonzalo, J., Trasobares, A., Hujala, T., Nordström, E.M., Borges, J.G., 2014. Computerized decision support tools to address forest management planning problems: history and approach for assessing the state of art world-wide. In Borges, J., Nordström, E.-M., Garcia Gonzalo, J., Hujala, T. (Eds.), Computer-Based Tools for Supporting Forest Management: The Experience and the Expertise WorldWide. SLU, Umea, pp. 3-25.

Gatica-Saavedra, P., Echeverría, C., Nelson, C.R., 2017. Ecological indicators for assessing ecological success of forest restoration: a world review. Restor. Ecol. 25, 850-857. http://dx.doi.org/10.1111/rec.12586.

Gholamzadeh Chofreh, A., Goni, F.A., Ismail, S., Mohamed Shaharoun, A., Klemeš, J.J., 
Zeinalnezhad, M., 2016. A master plan for the implementation of sustainable enterprise resource planning systems (part I): concept and methodology. J. Clean. Prod. 136, 176-182. http://dx.doi.org/10.1016/j.jclepro.2016.05.140.

Gordon, S.N., Floris, A., Boerboom, L.G.J., Lämås, T., Eriksson, L.O., Nieuwenhuis, M., Garcia, J., Rodriguez, L.C.E., 2013. Studying the use of forest management decision support systems: an initial synthesis of lessons learned from case studies compiled using a semantic wiki. Scand. J. For. Res. Press. 13, 37-41. http://dx.doi.org/10. 1080/02827581.2013.856463.

Hujala, T., Khadka, C., Wolfslehner, B., Vacik, H., 2013. Review. Supporting problem structuring with computer-based tools in participatory forest planning. For. Syst. 22, 270-281. http://dx.doi.org/10.5424/fs/2013222-03006.

Jannuzzi, C., Falsarella, O., Sugahara, C., 2014. Sistema de informação: um entendimento conceitual para a sua aplicação nas organizações empresariais Information system: a conceptual understanding for application in business organisations. Perspect. em Ciência da Informação 19, 94-117. http://dx.doi.org/10.1590/1981-5344/1927.

McDill, M. 2014. An overview of forest management planning and information management. In: Borges, G.J., Diaz-Balteiro, L., McDill, E.M., Rodriguez, C.E.L. (Eds.), The Management of Industrial Forest Plantations. Springer Netherlands, Dordrecht, pp. 27-59. http://dx.doi.org/10.1007/978-94-017-8899-1_2.

McElroy, M.W., 2000. The new knowledge management. Knowl. Innov. J. KMCI 1, 43-67. http://dx.doi.org/10.1016/S0024-6301(03)00076-1.

Meng, X., Minogue, M., 2011. Performance measurement models in facility management: a comparative study. Facilities 29, 472-484. http://dx.doi.org/10.1108/ 02632771111157141.

Nemati, H.R., Steiger, D.M., Iyer, L.S., Herschel, R.T., 2002. Knowledge warehouse: an architectural integration of knowledge management, decision support, artificial in telligence and data warehousing. Decis. Support. Syst. 33, 143-161. http://dx.doi. org/10.1016/S0167-9236(01)00141-5.

Nobre, S., Eriksson, L.-O., Trubins, R., 2016. The use of decision support systems in forest management: analysis of FORSYS country reports. Forests 7, 72. http://dx.doi.org/ 10.3390/f7030072.

Ocampo-Melgar, A., Valls, A., Alloza, J.A., Bautista, S., 2016. Fuzzy rule-based decision support system for evaluation of long-established forest restoration projects. Restor. Ecol. 24, 298-305. http://dx.doi.org/10.1111/rec.12325.

Park, J., Jeong, H.Y., 2013. The QoS-based MCDM system for Saa S ERP applications with social network. J. Supercomput. 66, 614-632. http://dx.doi.org/10.1007/s11227012-0832-4.

Plunkett, P., 2001. Managing Knowledge @ Work. Washington, DC, USA.

Rauscher, H.M., Schmoldt, D.L., Vacik, H., 2007. Information and knowledge management in support of sustainable forestry: a review. In: Sustainable Forestry: From Monitoring and Modelling to Knowledge Management and Policy Science, pp. 439-460.

Ray, D., Petr, M., Mullett, M., Bathgate, S., Marchi, M., Beauchamp, K., 2017. A simulation-based approach to assess forest policy options under biotic and abiotic climate change impacts: a case study on Scotland's National Forest Estate. For. Policy Econ. 0-1. http://dx.doi.org/10.1016/j.forpol.2017.10.010.

Revans, R., 2014. ABC of action learning. In: Action Learning: Research and Practice, http://dx.doi.org/10.1080/14767333.2014.909234.

Reynolds, J.H., Knutson, M.G., Newman, K.B., Silverman, E.D., Thompson, W.L., 2016. A road map for designing and implementing a biological monitoring program. Environ.
Monit. Assess. 188. http://dx.doi.org/10.1007/s10661-016-5397-x.

Rist, L., Felton, A., Mårald, E., Samuelsson, L., Lundmark, T., Rosvall, O., 2016. Avoiding the pitfalls of adaptive management implementation in Swedish silviculture. Ambio 45, 140-151. http://dx.doi.org/10.1007/s13280-015-0750-9.

Rodrigues, R.R., Padovezi, A., Farah, F.T., Viani, R., Barreto, T.E., Brancalion, P.H.S., 2013. Protocolo de monitoramento para programas/projetos de restauração florestal, Pacto pela Restauração da Mata Atlântica. São Paulo.

Rohde, M., Brödner, P., Stevens, G., Betz, M., Wulf, V., 2016. Grounded design - a praxeological IS research perspective. J. Inf. Technol. http://dx.doi.org/10.1057/jit. 2016.5 .

Saade, R.G., Nijher, H., 2016. Critical success factors in enterprise resource planning implementation. A review of case. J. Enterp. Inf. Manag. 29, 72-96.

Shohet, I.M., Nobili, L., 2016. Enterprise resource planning system for performancebased-maintenance of clinics. Autom. Constr. 65, 33-41. http://dx.doi.org/10.1016/ j.autcon.2016.01.008.

Thompson, J.J., 2014. Incorporación del monitoreo en la toma de decisiones y el manejo adaptativo. In: María, E., Zaccagnini, E., Goijman, A.P., Conroy, M.J., Thompson, J.J. (Eds.), Toma de Decisiones Estructuradas Para El Manejo Adaptativo de Recursos Naturales Ambientales En Ecosistemas Productivos. Inta Ediciones, Buenos Aires Argentina, pp. 15.

Tyndale, P., 2002. A taxonomy of knowledge management software tools: origins and applications. Eval. Program Plann. 25, 183-190. http://dx.doi.org/10.1016/S01497189(02)00012-5.

Vacik, H., Lexer, M.J., 2013. Past, current and future drivers for the development of decision support systems in forest management. Scand. J. For. Res. 7581, 1-18. http://dx.doi.org/10.1080/02827581.2013.830768.

Vacik, H., Torresan, C., Hujala, T., Khadka, C., Reynolds, K.M., 2013. The role of knowledge management tools in supporting sustainable forest management. For. Syst. 22, 442-455. http://dx.doi.org/10.5424/fs/2013223-02954.

Viani, R.A.G., Holl, K.D., Padovezi, A., Strassburg, B.B.N., Farah, F.T., Garcia, L.C., Chaves, R.B., Rodrigues, R.R., Brancalion, P.H.S., 2017. Protocol for monitoring tropical forest restoration: perspectives from the atlantic forest restoration pact in Brazil. Trop. Conserv. Sci. 10. http://dx.doi.org/10.1177/1940082917697265.

Waddill, D.D., Marquardt, M., 2003. Adult learning orientations and Action Learning. Hum. Resour. Dev. Rev. 2, 406-429. http://dx.doi.org/10.1177/ 1534484303258662

Watson, D.M., Doerr, V.A.J., Banks, S.C., Driscoll, D.A., van der Ree, R., Doerr, E.D., Sunnucks, P., 2017. Monitoring ecological consequences of efforts to restore landscape-scale connectivity. Biol. Conserv. 206, 201-209. http://dx.doi.org/10.1016/j. biocon.2016.12.032.

Whisenant, S.G., 1999. Reparing Damaged Wildlands Landscape-Scale Approach, University Press, Cambridge. Cambridge University Press, Cambridge.

White, M.A., Cornett, M.W., Wolter, P.T., 2017. Two scales are better than one: monitoring multiple-use northern temperate forests. For. Ecol. Manag. 384, 44-53. http://dx.doi.org/10.1016/j.foreco.2016.10.032.

Zakia, M.J., 2013. Estudos e propostas de instrumentos para viabilização de Plano de Florestas Nativas com finalidade econômica. São Paulo.

Zakia, M.J., Pinto, L.F.G., 2014. Guide for application of the new forest law to rural properties. In: Imaflora - Institue of Forest Managenet and Certification Florestais and IPEF, 2nd ed. Institute of Research and Forestry Studies, Piracicaba - SP. 